\section{TRENDS \& ISSUES}

in crime and criminal justice
Australian Government

Australian Institute of Criminology

November 2006

\title{
An investigation into the effective and ethical interviewing of suspected sex offenders
}

\author{
Mark Kebbell, Emily Hurren and Paul Mazerolle
}

Sexual assault is the offence least likely to be reported to police and, when reported, often does not proceed to court (Lievore 2005). Two reasons for this are victim reluctance to relive the experience in testimony and cross examination, and the difficulty of presenting a case with no witnesses to corroborate evidence. Research by the Institute (Taylor \& Joudo 2005) has shown how difficult it is to secure convictions in adult sexual assault cases. The study reported here investigates ways of improving the likelihood of a guilty offender confessing and is based on interviews with offenders and police. The authors suggest that the credibility of the evidence and the manner in which it is presented to the suspect can affect the likelihood of securing a confession. Although the numbers in the study are relatively small, they are indicative of practical measures that have the potential to improve the efficacy of the criminal justice system for victims of sexual assault. The broader impact would be in considerable benefits accruing to the judicial system.

\section{Toni Makkai}

Director

\section{Introduction}

Unlike most other criminal offences, sex offences usually occur within personal settings with few, if any corroborating witnesses, so a conviction may rely on the victim's word against that of the offender (Queensland. Crime and Misconduct Commission 2003). If an offender confesses to an investigator, three important advantages may result:

- the likelihood of a conviction being secured is greatly increased

- the likelihood of the victim having to give evidence in court is reduced, as is the negative impact on the victim from testifying about their abuse (Eastwood \& Patton 2002)

- a lengthy trial can often be avoided, thereby reducing the financial burden of prosecution.

Despite these arguments, comparatively few studies have investigated ways of increasing confessions from guilty suspects. Nevertheless, there is some evidence to suggest that key factors such as evidence, humanity and dominance, minimisation and maximisation, ethical interviewing and an understanding of cognitive distortions may have an impact on confession rates. These factors and their effect on confession rates are discussed in this paper.

Gudjonsson and Petursson (1991) asked 74 Icelandic prisoners why they had decided to confess to their crimes. The majority (55\%) identified the belief that the police would be able to prove that they did it as being critical to their decision to confess. Similarly, Moston, Stephenson and Williamson (1992) investigated confession rates for 1,067 suspects who had been interviewed by detectives. The majority of cases concerned non-sex offences. The results showed that when the researchers rated the evidence against the suspect as weak, confessions occurred less than 10 percent of the

ISSN 0817-8542

ISBN 1921185228

GPO Box 2944

Canberra ACT 2601 Australia

Tel: 0262609272 Fax: 0262609293

For a complete list and the full text of the papers in the Trends \& issues in crime and criminal justice series, visit the AIC website at: http://www.aic.gov.au

\section{Disclaimer:}

This research paper does not necessarily reflect the policy position of the Australian Government. 
time and denials occurred 77 percent of the time. When the evidence was rated as strong, confessions were frequent, occurring in 67 percent of cases, while denials were infrequent, occurring in 16 percent of cases. Presentation of evidence therefore raises some intriguing empirical issues, for example, the question of what suspects perceive to be strong evidence and how police can present evidence.

Holmberg and Christianson (2002) surveyed 83 men convicted of murder or sex offences. They found that aggression, hostility, and insulting and condemning behaviour by the interviewer, which they labelled 'dominance', reduced the likelihood of a confession. However, friendliness, with the suspect feeling acknowledged and respected as a human being, and having a feeling of cooperation, which they labelled 'humanity' were associated with increases in the numbers of confessions. The fact that the humanity approach can be successful could be explained by offenders feeling more comfortable with the officer, and more able to reduce their guilt by confessing and getting things off their chest, particularly if compared with an officer who displays dominance. Suspects are likely to be particularly sensitive to the way in which they are interviewed, and this should be borne in mind when devising effective and ethical police interviewing techniques. In this research, the variable of ethical interviewing is characterised by factors such as neutrality, and allowing the suspect time to comment (Milne \& Bull 1999).

Minimisation and maximisation can be described as minimising the consequences of confessing and maximising the consequences of not confessing (Inbau, Reid \& Buckley 1986). For example, an investigator could use minimisation by saying that although the crime was wrong other people have done worse than the suspect. Maximisation may emphasise the impact the crime has had on the victim. One of the few studies into the efficacy of this technique is that by Russano et al. (2005). In this experiment, participants were asked by a confederate to help cheat in an experimental task. Most did so and were later accused of cheating by the experimenter. Russano et al. (2005) used a minimisation condition. The results indicated that without any tactics, 46 percent of the guilty participants confessed but 81 percent confessed with the use of minimisation.

Sex offenders may have particularly distorted ways of thinking about their victims, which supports their offending (Swaffer et al. 1999). For example, many who offend against children agree with statements such as 'Having sex with a child is a good way for an adult to teach the child about sex', or 'A child who doesn't physically resist an adult's sexual advances, really wants to have sex with the adult', and 'when a young child walks in front of me with no or only a few clothes on, she is trying to arouse me (Abel et al. 1989). It is possible that showing an understanding of these distortions could increase the likelihood of an offender confessing, due to an increased level of comfort and a feeling of being understood. This issue of cognitive distortions is an issue worthy of further study.

The focus of this research project was to identify ways of improving police interviewing of suspected sex offenders and identifying factors that might increase the likelihood of a guilty offender confessing. The research uses interviews with convicted sex offenders in the first study, surveys of convicted sex offenders in the second study, experimental laboratory methods in the third study and interviews with experienced police officers in the fourth study. For brevity it does not summarise the findings of each study, instead synthesising the findings in the conclusion.

\section{Study 1: Qualitative study of convicted sex offenders' perceptions of police interviewing}

The key aims of this study were to ask convicted sex offenders questions regarding the feelings they experienced during their most recent police interview, and their reasons for confessing or denying. Participants were also asked to make suggestions on how to improve police interviewing of suspected sex offenders in future. Nineteen incarcerated sex offenders were interviewed individually using a semi-structured interview. Seventeen had made confessions.

Participants typically reported feeling anxious, guilty, and upset. For example, one offender described his feelings prior to interview as 'Complete state of nervousness...thinking of what else will come up, thinking of coming to jail, how the media was going to handle it'. Participants' responses indicated that about half had not decided whether they would confess or deny before they were interviewed. This indicates that interviewing officers have considerable potential to influence whether an offender confesses or denies. Participants' own reasons for confessing were similar to those reported by Gudjonsson and Petursson (1991) with a greater number of participants mentioning feelings of guilt. For example, one gave the following reason, 'Sick of my own behaviour. It was playing on my mind all the time. The guilt, everything'. A smaller proportion of respondents mentioned the strength of evidence.

Concerning reasons why an offender should confess, participants emphasised the importance of confessing to receive a more lenient sentence, that it was easier than denying, and that they would feel less guilty afterwards. They suggested that for police officers to obtain more confessions, interviews should follow a fair, compassionate, non-aggressive, and honest approach, with one offender stating, 'police officers could be more understanding....instead of coming on to you like you are the worst of the worst'.

When participants were asked for reasons for denying, the most frequent reason stated was to avoid being convicted of crimes they have or have not committed, suggesting that police officers should be cautious of accusing individuals of crimes where there is little evidence. For example, one offender stated that offenders would be more likely to deny if officers were, '....hitting 
you with more charges or offences than you did'. Some emphasised that exaggerating offences also made them think about denying, as they felt the interview process was not fair. The most frequent response concerning what the police could do to make people less likely to confess was behaving aggressively. For example one respondent stated, '... if you are aggressive towards people, they tend to get their back up. They dig in, they say, well I'm not going to tell you what you want to know'.

\section{Study 2: Quantitative study of sex offenders' perceptions of police}

The key aim of the second study was to collect quantitative data concerning convicted sex offenders' perceptions of their own police interview and effective interview practices. Forty-four male inmates of three state correctional centres who had been convicted of a sex crime agreed to participate. The primary research materials consisted of two, 35-item related questionnaires. The first questionnaire concerned participants' perceptions of how their own most recent police interview was conducted by the police. The second concerned how participants believed an ideal police interview should be conducted by the police to elicit a confession from a guilty offender.

Five questions were asked in each of seven categories. The interviewing strategies under examination were:

- humanity, e.g. my police interviewer showed sympathy towards me

- dominance, e.g. my police interviewer was aggressive towards me

- minimisation, e.g. my police interviewer said that although the crime was wrong, other people have done worse than me

- maximisation, e.g. my police interviewer said that I would feel worse if I did not confess

- cognitive distortions, e.g. my police interviewer suggested to me, that I may have believed the victim encouraged me to commit the offence
- $\quad$ strength of evidence, e.g. my police interviewer emphasised the strength of the evidence against me

- ethical interviewing, e.g. my police interviewer gave me time to comment.

Participants were required to rate each item on a five-point Likert scale from 1 (strongly disagree) to 5 (strongly agree). Data were analysed with MANOVAs. Significant follow-up F-tests $(\mathrm{p}<.05)$ are reported in the following tables.

The results are consistent and clear. Table 1 shows that those who confessed perceived their interview to have been more ethical than those who chose to deny. Offenders also suggested that increasing the ethical standard of the interview would increase the likelihood of a hypothetical guilty suspect confessing. Similarly, sex offenders who confessed perceived their interviewer to have displayed more humanity than those who denied. Offenders suggested that humanity should be increased compared with their own police interview to increase the likelihood of a confession occurring. Those who confessed perceived their interviewer to have displayed less dominance than those who denied. Offenders suggested that if dominance were reduced compared with their own police interview the likelihood of a confession occurring would be increased. Table 2 shows the means and standard deviations of offenders' perceptions of their own interview compared with what they rated as an ideal interview for facilitating a confession from the guilty.

There was no significant difference between confessors and deniers on their perceptions of whether minimisation or maximisation was used during their interviews. However, offenders did
Table 1: Sex offenders' perceptions of police interviewing strategies (means and standard deviations)(a) $^{(\mathrm{a})}$

\begin{tabular}{|c|c|c|c|c|}
\hline & \multicolumn{2}{|c|}{ Deniers $(n=12)$} & \multicolumn{2}{|c|}{ Confessors $(n=25)$} \\
\hline & M & SD & M & SD \\
\hline Ethical ${ }^{\star}$ & 1.97 & 0.82 & 3.14 & 0.93 \\
\hline Humanity* & 1.85 & 0.87 & 2.80 & 0.85 \\
\hline Dominance $^{\star}$ & 3.97 & 1.01 & 2.98 & 0.99 \\
\hline Minimisation & 2.12 & 0.81 & 2.35 & 0.58 \\
\hline Maximisation & 2.42 & 1.34 & 2.66 & 0.70 \\
\hline Strength of evidence* & 2.12 & 0.84 & 2.68 & 0.62 \\
\hline Cognitive distortions ${ }^{\star}$ & 1.97 & 0.71 & 2.37 & 0.45 \\
\hline
\end{tabular}

*statistically significant at $\mathrm{p}<.05$

(a) $1=$ low, $5=$ high
Table 2: Sex offenders' ratings of their own interview experience and of how the police should interview to obtain confessions from guilty suspects (means and standard deviations) $)^{(a)}$

\begin{tabular}{lccccc} 
& \multicolumn{2}{c}{ Own interview } & & \multicolumn{2}{c}{ Ideal interview } \\
\cline { 2 - 3 } \cline { 5 - 6 } & $\mathbf{M}$ & SD & & $\mathbf{M}$ & SD \\
Ethical $^{*}$ & 2.78 & 1.03 & & 4.37 & 0.40 \\
Humanity $^{*}$ & 2.49 & 0.94 & & 3.69 & 0.47 \\
Dominance* $^{*}$ & 3.29 & 1.07 & & 1.92 & 0.44 \\
Minimisation & 2.28 & 0.66 & & 2.72 & 0.66 \\
Maximisation & 2.58 & 0.93 & & 3.12 & 0.72 \\
Strength of evidence $^{*}$ & 2.52 & 0.74 & & 3.96 & 0.54 \\
Cognitive distortions $^{*}$ & 2.24 & 0.56 & & 2.86 & 0.65
\end{tabular}

*statistically significant at $p<.05$

(a) $1=$ low, $5=$ high; $n=38$ 
suggest that a confession would be more likely if more minimisation and maximisation strategies were used by police interviewers. Similarly, those who confessed perceived their interviewer to have displayed a greater understanding of sex offenders' cognitive distortions than those who chose to deny. Offenders suggested that increasing displays of an understanding of cognitive distortions would increase the likelihood of a guilty suspect confessing.

Those who confessed perceived their interview to have included more evidence presenting strategies than those who chose to deny, and offenders suggested that increasing the number of evidence presenting strategies would increase the likelihood of a guilty suspect confessing.

\section{Study 3: Experimental manipulations of the presentation of evidence}

The key aim of this study was to investigate witness evidence presenting strategies. Police officers often do not elicit as much accurate information from victims and witnesses as is possible and often do not remember all that they have elicited (Milne \& Bull 1999). This study was designed to determine what impact this might have. Mock suspects were used for ethical reasons because using real suspect interviews to test the hypotheses could potentially lead a suspect who might have confessed into denying.

Forty undergraduate participants were asked to commit a mock crime that involved them stealing a mobile phone. Later the mock offenders were questioned and evidence was presented to them from a witness who was said to have seen the offence. Participants were randomly assigned to one of two conditions:

- witness statement containing detailed information concerning their description and their actions

- witness statement containing no detailed information concerning their description and their actions.

For half the participants in each condition the information was correct, while for the other half some of the information was incorrect. Participants would gain or lose money depending on whether they were convicted or acquitted by a mock jury.

A logit model was run on participants' decisions to confess or deny as the dependant variable, with detail and accuracy as independent variables.

There was no significant effect for detail, but there was for accuracy. Fifteen participants confessed in the accurate condition compared with three in the inaccurate condition. This suggests that police officers should take care to present accurate evidence to suspects, an important point given that a great deal of eyewitness evidence appears to be potentially inaccurate (Milne \& Bull 1999).

\section{Study 4: Qualitative study of police officers' perceptions of sex offender interviews}

The key aim of this study was to ask experienced police officers about their beliefs concerning conducting effective interviews with suspected sex offenders. The participants were 13 police officers of the Queensland Police Service working in the area of child abuse and sexual assault investigation. The specific questions asked during each interview were:

- Could you start by sharing your views about how suspected offenders should and are being interviewed?

- How would you describe a typical suspected sex offender?

- Does interviewing suspected sex offenders differ from interviewing suspected non-sex offenders?

- Tell me about the aspects related to the interview that impact on whether a suspected sex offender confesses or denies.

From the interviews, it appears that officers generally believe that there is no typical sex offender and therefore no typical approach to interviewing these types of offenders. They also appear to understand the considerable stigma associated with these offences, with one officer stating, 'that stigma is the reason why it is very hard to get any truth out of them...unless they are confronted with all the facts'. It was common for the participants to identify the importance of establishing rapport and putting the suspect at ease at the outset of interview. As one officer commented, ' ... obviously the whole rapport building thing which we all embrace... a lot of that is pretty important'. A humane approach to interviewing was more likely to be recommended than a dominant approach. For example, one officer said, '.... if you treat the suspect as you would want to be treated I think that in many cases you would get cooperation...'.

Legislative and policy restrictions, such as informing the suspect of their legal rights and legal advice from solicitors, were identified as factors which impact on the way an interview with a suspect is conducted and the likelihood of a suspect confessing or denying during that interview. One officer commented on how strict the legislation is as follows, 'well we had to stand up in an interview one day and that was deemed to be oppressive...you know I have heard of interviews being thrown out because the police officer stood up, you know, and he said he was having a stretch but it was deemed to be intimidating...that is how unnatural the setting is...'.

Evidence was also often identified as a very important factor in the suspect's decision to confess or deny. For example, one officer stated 'well for a start you usually have a problem; the only thing you are going to have most of the time is one word versus another'. Similarly, another stated 'you do sort of lay your cards on the table to a degree just to be sure that they realise where you're coming from and that you do have a strong case or something like that, it may be a case that you have to show your cards but yeah sometimes that is just what you have to do to get as much information as you can to get a confession of some sort'.

Other factors such as parental status, proximity to the victim and relationship with the victim, guilt, shame, personality, 
socioeconomic status, education, and offending history, were also identified. For example, one officer commented 'Some ... don't want to put their children through the court process so therefore are prepared to admit their guilt...'.

\section{Conclusions}

Each methodology used here has its strengths and weaknesses. The principle limitation of the self-report studies is that it is necessary to rely on offenders' and police officers' perceptions of what occurs in interviews. Clearly, discrepancies may exist between perceived or stated versions of reality and reality itself. Similarly, the laboratory study offers control but with reduced ecological validity. Future work could use taped suspect interviews for analysis to triangulate this study's findings. Nevertheless, this approach would have the major drawback that many recorded suspect interviews appear to occur after an off-tape interview and so may not reveal a true picture of what happened (see Dixon 2005; Mallard v The Queen 2005).

Synthesising the four studies allows some conclusions to be made. Other researchers have shown that police officers usually elicit less detailed and accurate accounts than are possible from eyewitnesses and then have difficulty remembering that account so that they may be poor at presenting this evidence in a credible way to a suspect (Milne \& Bull 1999). Given that all four studies indicated that evidence is likely to play an important part in many suspects' decision to confess or deny, the implication is that evidence, especially eyewitness evidence, must be conscientiously collected, familiarised, and presented to the suspect in a convincing way. Specific ways in which police officers can improve their presentation of evidence to suspects need to be devised and evaluated.

The results of studies one, two and four suggest that police officers should approach suspected sex offenders in an open-minded manner that displays humanity rather than dominance, to maximise the likelihood of a confession. Again, quite how these strategies can be communicated to suspected sex offenders is worthy of future research. Importantly, as indicated by study four, experienced police officers, in sex crime investigation in Queensland at least, seem to be supportive of these approaches and have considerable insight into how effective interviews should be conducted.

Studies one and two suggest that minimisation, maximisation, and displaying an understanding of cognitive distortions may also be effective strategies. Nevertheless, caution must be exercised to ensure compliance with legislation. For instance, minimisation could potentially be either legal and ethical, (for example a police officer saying 'perhaps you've been under a lot of stress recently') or illegal and unethical (for example a police officer saying 'I've met the victim and she deserved it'. Note: there is no suggestion that the latter approach is used in Queensland although it has been advocated in the United States; see Inbau, Reid \& Buckley (1986).

Nevertheless, police officers need to be clearly informed about what is legally permissible in suspect interviews. At present many officers are not clear about how the relevant legislation is interpreted, especially when terms are used in a nondefined and general manner. One police service in Australia (not the Queensland Police Service) is giving different interview scenarios to a judge to clarify what is, and is not, likely to be permissible. This may be an approach other police services wish to think about.

Taken together, the strategies outlined here are in theory likely to increase confessions from guilty suspects while treating them fairly. In turn, the likelihood of achieving justice for the victims of sex crime is potentially increased.

\section{Acknowledgments}

This project was supported by a grant from the Criminology Research Council and the Crime and Misconduct
Commission. The views expressed are the responsibility of the authors and are not necessarily those of the funding bodies.

The full report from the research project, An investigation into the effective and ethical interviewing of suspected sex offenders, is available online at http://www.aic.gov.au/crc/reports/ 200304-12.html

The assistance of the Queensland Department of Corrective Services and Queensland Police Service is gratefully acknowledged. The views expressed in this article do not necessarily represent those of the Department of Corrective Services or the Queensland Police Service.

\section{References}

Abel GG et al. 1989. The measurement of the cognitive distortions of child molesters. Annals of sex research 2: 135-153

Dixon D 2005. Regulating police interrogation. In Williamson T (ed), Investigative interviewing: developments in rights, research and regulation. Cullompton: Willan

Eastwood C \& Patton W 2002. The experiences of child complainants of sexual abuse in the criminal justice system. Canberra: Criminology Research Council

GH \& Petursson H 1991. Custodial interrogation: why do suspects confess and how does it relate to their crime, attitude and personality? Personality and individual differences 12: 295-306

Holmberg U \& Christianson S 2002. Murderers' and sexual offenders' experience of police interviews and their inclination to admit or deny crimes. Behavioral sciences and the law 20: 31-45

Inbau FE, Reid JE \& Buckley JP 1986. Criminal interrogation and confessions, 3rd ed. Baltimore MD: Williams and Wilkins

Lievore D 2005. Prosecutorial decisions in adult sexual assault cases. Trends \& issues in crime and criminal justice no. 291

Mallard v The Queen [2005] HCA 68 (15 November 2005)

Milne R \& Bull R 1999. Investigative interviewing: psychology \& practice. Chichester: Wiley

Moston S, Stephenson GM \& Williamson TM 1992.

The effects of case characteristics on suspect behaviour during questioning. British journal of criminology 32: 23-40

Queensland. Crime and Misconduct Commission 2003. Seeking justice: an inquiry into the handling of sexual offences by the criminal justice system. Brisbane: Crime and Misconduct Commission Russano MB et al. 2005. Investigating true and false confessions within a novel experimental paradigm. Psychological science 16(6): 481-486

Swaffer T et al. 1999. An exploration of child sexual abusers cognitive distortions with special reference to the role of anger. Journal of sexual aggression 4: 31-44

Taylor N \& Joudo J 2005. The impact of pre-recorded video and closed circuit television testimony by adult sexual assault complainants on jury decision-making: an experimental study. Research and public policy paper no. 68. Canberra: Australian Institute of Criminology 


\section{Related AIC/CRC publications}

\section{5}

Lievore D. Prosecutorial decisions in adult sexual assault cases. Trends \& issues in crime and criminal justice no. 291

http://www.aic.gov.au/publications/ tandi2/tandi291.html

Taylor N \& Joudo J. The impact of pre-recorded video and closed circuit television testimony by adult sexual assault complainants on jury decision-making: an experimental study. Research and public policy series no. 68

http://www.aic.gov.au/publications/ rpp/68/

\section{4}

Allan A \& Dawson D. Assessment of the risk of re-offending by Indigenous male violent and sexual offenders. Trends \& issues in crime and criminal justice no. 280

http://www.aic.gov.au/publications/ tandi2/tandi280.html

Lievore D. Prosecutorial decisions in adult sexual assault cases: an Australian study: report prepared for the Office of the Status of Women http://www.aic.gov.au/publications/ reports/2004-10-decisions.html
Lievore D. Recidivism of sexual offenders: rates, risk factors and treatment efficacy: report prepared for the Office of the Status of Women

http://www.aic.gov.au/publications/ reports/2003-06-recidivism.html

Lievore D. Victim credibility in adult sexual assault cases. Trends \& issues in crime and criminal justice no. 288

http://www.aic.gov.au/publications/ tandi2/tandi288.html

Richards JC et al. Understanding male domestic partner abusers.

Trends \& issues in crime and criminal justice no. 283

http://www.aic.gov.au/publications/ tandi2/tandi283.html

\section{3}

Eastwood C. The experiences of child sexual abuse complainants in the criminal justice system. Trends \& issues in crime and criminal justice no. 250

http://www.aic.gov.au/publications/ tandi/tandi250.html

Lievore D. Non-reporting and hidden recording of sexual assault: an international literature review: report prepared for the Office of the Status of Women

http://www.aic.gov.au/publications/ reports/2003-06-review.html
Richards JC et al. Identification of characteristics and patterns of male domestic partner abusers http://www.aic.gov.au/crc/ reports/200001-04.html

\section{2}

Eastwood C \& Patton W. The experiences of child complainants of sexual abuse in the criminal justice system

http://www.aic.gov.au/crc/reports/ eastwood.html

\section{1}

Cook B, David F \& Grant A. Sexual violence in Australia. Research and public policy series no. 36

http://www.aic.gov.au/publications/ rpp/36/

\section{0}

Young M, Byles J \& Dobson A. The effectiveness of legal protection in the prevention of domestic violence in the lives of young Australian women. Trends \& issues in crime and criminal justice no. 148

http://www.aic.gov.au/publications/ tandi/tandi148.html Hurren and Professor Paul Mazerolle are at Griffith University.
General editor, Trends \& issues in crime and criminal justice series: Dr Toni Makkai, Director, Australian Institute of Criminology, GPO Box 2944 Canberra ACT 2601 Note: Trends \& issues in crime and criminal justice papers are peer reviewed.
The AIC is a statutory body with a Board of Management comprising Australian, state and territory government representatives, administered under the Criminology Research Act 1971. 